Shigehito Sato MD, Naomitsu Okubo MD, Soichiro Yamashita MD, Sumii Yamamoto MD, Megumi Kumagai MD, Shinichi Kihara MD, Harumi Nakayama MD

\title{
Age-related decrease in toe-thumb temperature difference with lumbar epidural anaesthesia
}

With lumbar epidural anaesthesia, big toe skin temperature increases and is associated with a compensatory decrease of thumb temperature. The purpose of the present study was to examine whether thumb-big toe temperature differences were affected by age. Following the attachment of temperature probes at the digital pad of the right big toe and the right thumb, lumbar epidural anaesthesia at $L_{2 / 3}$ was performed in $54 \mathrm{pa}$ tients with $10 \mathrm{ml}$ lidocaine $1.5 \%$. Big toe and thumb skin temperatures were measured continuously and recorded every minute. Fifteen minutes after epidural injection, the toe temperature increased $6.3 \pm 2.1^{\circ} \mathrm{C}(\Delta F)$ from the control value, $29.4 \pm$ $2.2^{\circ} \mathrm{C}$, and the thumb temperature decreased $-1.5 \pm 1.0^{\circ} \mathrm{C}$ $(\Delta H)$ from the control value, $31.6 \pm 2.8^{\circ} \mathrm{C}$. Regression coefficient between $\Delta T_{15}$ (toe-thumb skin temperature 15 min after epidural injection) and age was: $Y=-0.7 X+8.95(r=0.35$, $P<0.01 ; Y=\Delta T_{15}, X=$ age). The ratio of $\Delta H$ to $\Delta F$ and age was expressed as: $Y=0.51 X-46.57(r=0.41, P$ $<0.01: Y=\Delta H / \Delta F, X=$ age). It is concluded that, in lumbar epidural anaesthesia, the decrease of the thumb skin temperature is reduced with aging.

Pendant l'anesthésie épidurale lombaire, le température du gros orteil augmente et est associée avec une baisse compensatoire de la température du pouce. Cette étude vise à évaluer si les différences de température orteil-pouce sont affectées par l'âge. Après la mise en place de la sonde de température sur la pulpe du gros orteil et du pouce droits, une épidurale lombaire à $L_{2 / 3}$ est réalisé chez 54 patients avec $10 \mathrm{ml}$ de lidocaïne $1,5 \%$.

\section{Key words}

AGE FACTORS:

ANAESTHETIC TECHNIQUE: epidural;

ANAESTHETICS, LOCAL: lidocaine;

TEMPERATURE: skin.

From the Department of Anesthesiology, Institute of Clinical Medicine, University of Tsukuba, Tsukuba-shi, Ibaraki-ken, 305 Japan.

Address correspondence to: Dr. Shigehito Sato, Department of Anesthesiology, Institute of Clinical Medicine, University of Tsukuba, Tsukuba-shi, Ibaraki-ken, 305 Japan.

Accepted for publication 1st April, 1994.
Les températures cutanées du gros orteil et du pouce sont mesurée en continu et enregistrées à la minute. Quinze minutes après linjection épidurale, la température du gros orteil augmente de $6,3 \pm 2,1^{\circ} \mathrm{C}(\Delta F)$ comparativement aux valeurs de contrôle, $29,4 \pm 2,2^{\circ} \mathrm{C}$, et la température du pouce diminue de $-1,5 \pm 1,0^{\circ} \mathrm{C}(\Delta H)$ comparativement aux valeurs de contrôle, $31,6 \pm 2,8^{\circ} \mathrm{C}$. Le coefficient de régression entre $\Delta T_{15}$ (la température cutanée orteil-pouce 15 min après linjection épidurale) et l'âge est: $Y=-0,07 X+8,95(r=0,35, P<$ 0,01: $Y=\Delta T_{15}, X=$ âge). La relation de $\Delta H$ à $\Delta F$ avec l'âge s'exprime ainsi: $Y=0,51 X-46,57$ ( $r=0,41, P<0,01$ : $Y=\Delta H / \Delta F, X=\hat{a g e})$. On conclut que sous anesthésie épidurale que la baisse de la température cutanée du pouce diminue avec l'âge.

During spinal or lumbar epidural anaesthesia, the foot skin temperature increases due to blockade of the sympathetic nerves innervating the lower extremity blood vessels. With lumbar epidural anaesthesia, skin temperature increases in the foot (big toe) are associated with compensating decreases in the hand (thumb). ${ }^{1}$ Handa et al. demonstrated that the neural and hormonal regulation of vascular smooth muscle in the rat hind limb is impaired in old age. ${ }^{2}$ However, age-related changes between the increase in foot skin temperature and decrease in hand skin temperature due to lumbar epidural anaesthesia is unclear. In the present study, we measured the skin temperature changes in the foot and hand during lumbar epidural anaesthesia, and examined the relationship between the temperature differences in the foot and hand and the patient's age.

\section{Methods}

The protocol was approved by the Institutional human investigation committee of our hospital and informed consent was obtained from 62 patients. All patients were ASA physical status I or II without medical problems, history of diabetes mellitus, or hypertension. All were premedicated with $0.2 \mathrm{mg} \cdot \mathrm{kg}^{-1}$ diazepam and $75 \mathrm{mg}$ roxatidine acetate po $90 \mathrm{~min}$ before the start of anaesthesia. 
TABLE 1 Patient characteristics (minimum - maximum)

\begin{tabular}{lc}
\hline Age $(\mathrm{yr})$ & $44.4 \pm 14.7(22-70)$ \\
Height $(\mathrm{cm})$ & $158.5 \pm 7.5(148-172)$ \\
Weight $(\mathrm{kg})$ & $56.3 \pm 10.1(35.6-76)$ \\
\hline
\end{tabular}

Data are mean $\pm S D$.

Big toe and thumb skin temperatures were measured continuously with a deep body temperature apparatus, Core-Temp ${ }^{-10}$, Model CTM-204 (Terumo-Japan Co.) and recorded every minute. The temperature probes were attached at the digital pad of the right big toe and the right thumb with adhesive plaster (Elatex ${ }^{\circledR}$ ). The foot and arm were covered with cotton bandage (Orthex ${ }^{\circledR}$ ) to reduce the effect of ambient temperature. ${ }^{3}$ The CoreTemp(ii) thermometer is very simple to use in clinical practice and evaluates deep tissue temperature, not skin temperature. The surface probe of this apparatus weighs $7.0 \mathrm{~g}$, has a $8.5 \mathrm{~mm}$ diameter and comprises an electrical heating element and two thermistors separated by an insulator. When placed on finger or toe, it measures temperature near the centre of the digit. We used this deep temperature as a "skin temperature" in the present study, since this surface (deep) temperature is better correlated to sympathetic nerve activity than that of ordinary skin temperature. ${ }^{3}$

Ambient temperature in the operating rooms ranged between $22.0-25.0^{\circ} \mathrm{C}$. An 18-gauge $i v$ cannula was inserted into the left arm, and an intravenous infusion of lactated Ringer's solution was administered at a rate of $20 \mathrm{ml} \cdot \mathrm{kg}^{-1} \cdot \mathrm{hr}^{-1}$.

The ECG was monitored using precordial leads, and arterial blood pressure was monitored via a cuff on the left arm every $2.5 \mathrm{~min}$ (Dinamap $1846 \mathrm{SX}$, Critikon Inc.). In the right decubitus position, a Tuohy epidural needle was placed in the $L_{2 / 3}$ interspace using the balloon method. After confirming its ability to aspirate blood, $10 \mathrm{ml}$ lidocaine $1.5 \%$ were injected into the epidural space over $20 \mathrm{sec}$. Following the lidocaine injection, an epidural catheter was inserted promptly and the patient was turned into the supine position. Patients with a systolic blood pressure $<100 \mathrm{mmHg}$ or $<80 \%$ of baseline were treated with additional $i v$ fluid and, if necessary, boluses of ephedrine $5 \mathrm{mg} i$. The upper level of sensory blockade was determined by response to pin-prick tests at $15 \mathrm{~min}$ after epidural injection. Patients who showed an analgesic level above $T_{4}$ were excluded from the study.

Skin temperature differences from baseline to $15 \mathrm{~min}$ after injection were recorded. The ratio of thumb skin temperature decrease from control value $(\Delta \mathrm{H})$ to toe skin temperature increase from control value $(\Delta F)$ was expressed as $\Delta \mathrm{H} / \Delta \mathrm{F} \times 100$ (\%). Descriptive statistics are expressed as mean \pm standard deviation (SD).
TABLE II Changes in systolic blood pressure (SBP, $\mathrm{mmHg}$ ) and heart rate (HR, bpm) during $15 \mathrm{~min}$ following epidural injection

\begin{tabular}{|c|c|c|c|c|}
\hline & \multicolumn{4}{|l|}{ Time (min) } \\
\hline & 0 & 5 & 10 & 15 \\
\hline SBP & $115.6 \pm 17.4$ & $112.6 \pm 19.5$ & $119.9 \pm 18.3$ & $116.9 \pm 15.4$ \\
\hline HR & $71.2 \pm 13.4$ & $74.2 \pm 11.2$ & $71.1 \pm 13.0$ & $70.7 \pm 12.0$ \\
\hline
\end{tabular}

Data are mean $\pm S D$.

TABLE III Skin temperature changes $\left({ }^{\circ} \mathrm{C}\right)$ in toe, thumb and $\Delta \mathrm{T}$ (toe-thumb)

\begin{tabular}{lcccc}
\hline \multicolumn{4}{l}{ Time (min) } \\
\cline { 2 - 5 } & 0 & 5 & 10 & 15 \\
\hline Toe & $29.4 \pm 2.2$ & $30.6 \pm 2.4^{*}$ & $34.1 \pm 2.9^{*}$ & $35.8 \pm 1.0^{*}$ \\
Thumb & $31.6 \pm 2.8$ & $31.6 \pm 3.0$ & $30.8 \pm 2.9$ & $30.0 \pm 3.1^{*}$ \\
$\Delta \mathrm{T}$ & $-2.2 \pm 2.1$ & $-1.0 \pm 1.9^{*}$ & $3.3 \pm 2.8^{*}$ & $5.8 \pm 3.0^{*}$ \\
\hline
\end{tabular}

Data are mean $\pm S D$.

$* P<0.05$ vs 0 min.

ANOVA was used to compare systolic blood pressure (SBP), heart rate (HR), and skin temperatures between the control and post-epidural injection. Simple regression analysis was used to analyze the linear regression between skin temperature change and age. Differences were considered to be significant when $P<0.05$.

\section{Results}

No patients suffered complications or consequences as a result of participation in the present study. Eight patients were excluded because the sensory blockade level was above $T_{4}$. The patient characteristics, are listed in Table I. The time course of SBP and HR are shown in Table II. Five patients required additional fluid but none required ephedrine to maintain systolic blood pressure. Skin temperature changes in the toe and thumb are shown in Table III. Toe skin temperature increased above the base line at five minutes and thumb skin temperature decreased at $15 \min (P<0.01)$.

Fifteen minutes after the epidural injection, big toe temperature increased $6.3 \pm 2.1^{\circ} \mathrm{C}\left(\Delta \mathrm{F}\right.$ : range 2.7 to $\left.11.1^{\circ} \mathrm{C}\right)$ from the control values of $29.4 \pm 2.2^{\circ} \mathrm{C}$ and thumb temperature decreased $-1.5 \pm 1.0^{\circ} \mathrm{C}(\Delta \mathrm{H}$ : range -3.0 to $0.2^{\circ} \mathrm{C}$ ) from $31.6 \pm 2.8^{\circ} \mathrm{C}$. We could not find any correlation between decreases in thumb temperature and age. However, the skin temperature differences between the toe and thumb at $15 \mathrm{~min}$ become smaller with aging. Figure 1 shows a summative change of both toe and thumb temperature. The regression line was expressed as: $\mathrm{Y}=-0.07 \mathrm{X}+8.95(\mathrm{r}=0.35, P<0.01$ : $\mathrm{Y}=\Delta \mathrm{T} 15, \mathrm{X}=$ age). Age-related changes were also 




FIGURE I Relation between differences of skin temperature between thumb and big toe, and age.

demonstrated in the ratio of $\Delta \mathrm{H} / \Delta \mathrm{F}$. Figure 2 shows the ratio of change in hand and foot temperature. The regression line was expressed as: $\mathrm{Y}=0.51 \mathrm{X}-46.57$ ( $\mathrm{r}=0.41, P<0.01: \mathrm{Y}=\Delta \mathrm{H} / \Delta \mathrm{F}, \mathrm{X}=$ age).

The mean anaesthetic levels $15 \mathrm{~min}$ after epidural injection were $T_{9}-L_{4}$. There was no relationship between anaesthetic level and age.

\section{Discussion}

There was no correlation between the decrease in thumb temperature and age but $\Delta \mathrm{T}_{15}$ (toe-thumb skin temperature $15 \mathrm{~min}$ after epidural injection) became smaller with aging. An age-related decrease in the ratio of $\Delta \mathrm{H} / \Delta \mathrm{F}$ was also observed. Hence, with lumbar epidural anaesthesia, it appears that reflex temperature decrease in the hand finger becomes smaller in accordance with aging. Our results support previous observations that epidural anaesthesia or spinal anaesthesia leads to blood pooling in the denervated lower extremities and a reflex decrease in skin temperature of the innervated arms. ${ }^{4,5}$

Hopf et al. reported that the skin temperature increased at the foot (great toe: $8.5 \pm 2.5^{\circ} \mathrm{C}$ ), and decreased at the hand (thumb: $-3.1 \pm 2.1^{\circ} \mathrm{C}$ ) with lumbar epidural anaesthesia. ${ }^{1}$ Their temperature changes were much greater than those of our study. According to their report, toe skin temperature reached a plateau approximately $45 \mathrm{~min}$ after epidural injection. To avoid delay of surgery, our data were obtained $15 \mathrm{~min}$ after injection. Therefore, comparison of the results from the present study and theirs may be limited.

Cardiovascular impairment is an important functional manifestation of aging. The neurohumoral regulation of vascular smooth muscle may change with age and contribute to a loss in cardiovascular adaptation to circulatory disturbances. In elderly patients, arteriosclerosis can influence the results in the present study. Although

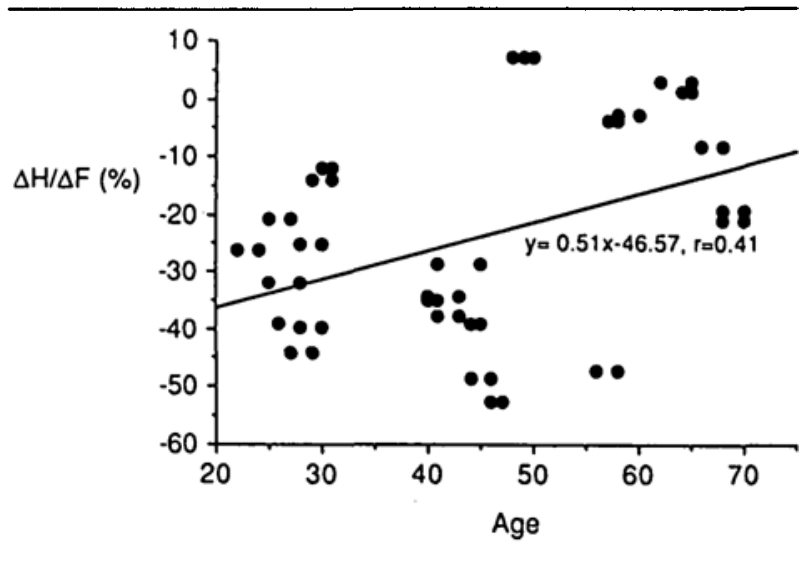

FIGURE 2 Relation between the ratio of decrease of thumb skin temperature $(\Delta \mathrm{H})$ to toe skin temperature $(\Delta \mathrm{F})$ and age.

studies of isolated blood vessels show no age-related change in sensitivity to norepinephrine in rat arteries ${ }^{6}$ or in human blood vessels, ${ }^{7,8}$ an age-related decrease in the systemic pressor response to phenylephrine has been demonstrated in humans. ${ }^{9}$ Moreover, increase in hind limb perfusion in response to lumbar sympathetic nerve stimulation was less in older rats than in younger animals. $^{2}$

Lundin et al. ${ }^{10}$ recorded direct skin sympathetic activity (SSA) to determine the magnitude of blockade of sympathetic fibres to the lower extremities during epidural anaesthesia. Epidural anaesthesia with an upper level of sensory blockade at $T_{4-8}$ completely blocked spontaneous SSA. However, the level of blockade up to $T_{10-11}$ produced only a partial sympathetic blockade. They concluded that sensory blockade at $T_{8}$ or above is needed to produce a complete sympathetic blockade to lower extremity. Arndt et al. observed the effects of vasomotor tone on intrathoracic and splanchnic blood volume using the distribution of radioactivity $\left({ }^{99 \mathrm{~m}} \mathrm{Tc}\right)$ labeled erythrocytes before and during epidural anaesthesia (Arndt). During epidural anaesthesia with a sensory block up to $\mathrm{T}_{4 / 5}$, radioactivity increased only in the denervated legs, whereas it decreased in all other regions in the thorax, the innervated upper limbs, and in the splanchnic vasculature." We excluded the eight patients who showed an anaesthesia level above $T_{4}$, because, in such cases, sympathetic nerves innervating the upper arm may also be blocked.

Although skin temperature is not the most sensitive method of evaluating regional blood flow, a good correlation between the change of skin temperature and blood flow in the hand has been demonstrated. ${ }^{12}$ Furthermore, sympathetic nerve activity can be directly evaluated using micro electrodes. Such evaluation by flowmetry and/or skin conductance response probably would 
have been appropriate in this study. ${ }^{13-15}$ Moreover the dose of lidocaine should have been defined based on a height criteria to eliminate the spread of anaesthetics to cephalad. In the present study, the metabolism of the premedications is quite likely to be affected by patient's age. Consequently, the premedication should have also been eliminated.

In conclusion, with lumbar epidural anaesthesia, the degree of reflex temperature decrease in the nonanaesthetized finger relative to the increase in the toe temperature becomes smaller in accordance with aging.

\section{References}

1 Hopf HB, Weissbach B, Peters J. High thoracic segmental epidural anesthesia diminishes sympathetic outflow to the legs, despite restriction of sensory blockade to the upper thorax. Anesthesiology 1990; 73: 882-9.

2 Handa RK, Duckles SP. Age-related changes in adrenergic vasoconstrictor responses of the rat hindlimb. Am J Physiol 1987; 253: H1566-72.

3 Sato S, Yamaguchi H, Okubo N, Fukuda T, Naito $H$. Change in skin temperature as a guide to timing supplementary doses during epidural anesthesia. Japanese Anaesthesia Journals Review 1989; 3: 127-30.

4 Shimosato $S$, Etsten $B E$. The role of the venous system in cardiocirculatory dynamics during spinal and epidural anesthesia in man. Anesthesiology 1969; 30: 619-25.

5 Bonica JJ, Akamatsu TJ, Berges PU, Morikawa K, Kennedy WF Jr. Circulatory effects of peridural block: II. Effects of epinephrine. Anesthesiology 1971; 34: 514-22.

6 Duckles SP, Carter BJ, Williams CL. Vascular adrenergic neuroeffector function does not decline in aged rats. Circ Res 1985; 56: 109-16.

7 Scott PJW, Reid JL. The effect of age on the repsonses of human isolated arteries to noradrenaline (Letter). $\mathrm{Br} \mathrm{J}$ Clin Pharmacol 1982; 13: 237-9.

8 Stevens MJ, Lipe S, Moulds RFW. The effect of age on the responses of human isolated arteries and veins to noradrenaline (Letter). Br J Clin Pharmacol 1982; 14: 750-1.

9 Elliot HL, Sumner DJ, McLean K, Reid JL. Effect of age on the responsiveness of vascular $\alpha$-adrenoceptors in man. J Cardiovasc Pharmacol 1982; 4: 388-92.

10 Lundin S, Kirnö K, Wallin BG, Elam M. Effects of epidural anesthesia on sympathetic nerve discharge to the skin. Acta Anaesthesiol Scand 1990; 34: 492-7.

11 Arndt JO, Höck A, Stanton-Hicks $M$, Stühmeier $K-D$. Peridural anesthesia and the distribution of blood in supine humans. Anesthesiology 1985; 63: 616-23.

12 Malmqvist ELÅ, Bengtsson M, Sörensen J. Efficacy of stellate ganglion block: a clinical study with bupivacaine. Reg Anesth 1992; 17: 340-7.

13 Malmqvist $L-\AA$, Tryggvason B, Bengtsson $M$.
Sympathetic blockade during extradural analgesia with mepivacaine or bupivacaine. Acta Anaesthesiol Scand 1989; 33: 444-9.

14 Bengtsson $M$. Changes in skin blood flow and temperature during spinal analgesia evaluated by laser Doppler flowmetry and infrared thermography. Acta Anaesthesiol Scand 1984; 28: 625-30.

15 Bengtsson $M$, Nilsson $G E$, Löfström JB. The effect of spinal analgesia on skin blood flow evaluated by laser Doppler flowmetry. Acta Anaesthesiol Scand 1983; 27: 206-10. 